\title{
Theoretical and Experimental Studies of Doping Effects on Thermodynamic Properties of (Dy, Y)- $\mathrm{ZrO}_{2}$
}

\author{
Liu Qu ${ }^{\mathrm{a}}$, Kwang-Leong Choy ${ }^{\mathrm{a}, *}$, Richard Wheatley ${ }^{\mathrm{b}}$ \\ ${ }^{a}$ UCL Institute for Materials Discovery, University College London, London, WC1E 6BT, \\ UK \\ ${ }^{b}$ Department of Chemistry, University of Nottingham, Nottingham, NG7 2RD, UK \\ * Corresponding Author: Tel/fax: +44(0)2076793855. \\ E-mail address: k.choy@ucl.ac.uk (K.-L. Choy)
}

\begin{abstract}
Ionic oxide materials play a vital role in technical applications owing to their hightemperature capability and when used as thermal barrier coating (TBC) materials, for example, they have environmentally friendly effects such as improved fuel efficiency and reduced emissions. Doped $\mathrm{ZrO}_{2}$ based solid solution is attracting attention, whereas doping effects on thermodynamic properties are not well understood. This work reports the synthesis and characterization of doped $\mathrm{ZrO}_{2}$ with $\mathrm{Dy}^{3+}$ and $\mathrm{Y}^{3+}$ via a sol-gel route. The relationship between chemical composition and thermodynamic properties is investigated via experiment and molecular dynamics (MD) simulation. MD simulation has been employed to theoretically explore the crystal structure and to calculate the intrinsic thermal conductivity, which agrees well with the experiment measurement. The thermal conductivity of dense samples is lower than that of conventional 8 wt. $\% \mathrm{Y}_{2} \mathrm{O}_{3}$ stabilized $\mathrm{ZrO}_{2}$ (equivalent to $4 \mathrm{~mol} \% \mathrm{Y}_{2} \mathrm{O}_{3}$ stabilized $\mathrm{ZrO}_{2}, 4 \mathrm{YSZ}$ ) at room temperature. The coefficient of thermal expansion is higher due to the doping $\mathrm{Dy}^{3+}$ ion compared with that of 4YSZ. The thermochemical compatibility of Dy0.06 $\mathrm{Y}_{0.072} \mathrm{Zr}_{0.868} \mathrm{O}_{1.934}$ with $\mathrm{Al}_{2} \mathrm{O}_{3}$ which is critical for the durability of the TBC system has been studied and can be maintained up to $1500^{\circ} \mathrm{C}$.
\end{abstract}

Keywords: Thermal conductivity; coefficient of thermal expansion; molecular dynamics simulation; ceramic oxide 


\section{Introduction}

Rare earth doped YSZ can be widely used in applications such as solid oxide fuel cells, oxygen sensors, TBCs, thermographic phosphors and photonic devices, thanks to the chemical stability, oxygen ion conductivity, thermodynamic properties and luminescence properties [1-5]. Low thermal conductivity and a relatively high coefficient of thermal expansion enable the 4YSZ to be used as ceramic TBCs in aero rotating components to enhance the temperature of the allowable gas and to increase the aero engine efficiency $[6,7]$. The limitation of $4 \mathrm{YSZ}$ is the operation temperature $\left(\sim 1200^{\circ} \mathrm{C}\right)$ above which a phase transformation would occur during the thermal cycling process, decreasing the durability and reliability of TBCs [8].

New ceramic TBC materials with various crystal structures and compositions have been widely investigated in order to develop alternative materials that enable a higher operation temperature. Rare earth oxide doped $\mathrm{ZrO}_{2}$ ceramics such as $\mathrm{A}_{2} \mathrm{Zr}_{2} \mathrm{O}_{7}$ pyrochlore structure, $\mathrm{A}_{2} \mathrm{~B}_{2} \mathrm{O}_{7}$ fluorite structure, $\mathrm{ABO}_{3}$ perovskite structure and magnetoplumbite $\operatorname{LnMB}_{11} \mathrm{O}_{19}$, $\left(\mathrm{Ln}=\mathrm{La}^{3+}\right.$ to $\mathrm{Gd}^{3+}, \mathrm{M}=\mathrm{Mg}^{2+}, \mathrm{Mn}^{2+}$ to $\mathrm{Zn}^{2+}, \mathrm{B}=\mathrm{Al}^{3+}$ and $\mathrm{Fe}^{3+}$ ) have been considered as promising candidates for new ceramic TBCs due to lower thermal conductivity and enhanced thermomechanical properties [8-11]. Co-doping on the A-site of pyrochlore oxide is reported to be effective in lowering the thermal conductivity than the un-doped pyrochlore oxide [12]. $\left(\mathrm{La}_{1-\mathrm{x}} \mathrm{Yb}_{\mathrm{x}}\right)_{2} \mathrm{Zr}_{2} \mathrm{O}_{7}$ pyrochlore ceramics exhibited a quasi-eutectoid mixture with significantly lower thermal conductivity attributed to enhanced scattering of phonons [13]. However, the overall performance of new compositions with respect to the thermochemical compatibility, the fracture toughness, and the coefficient of thermal expansion is critical in controlling the reliability and durability of TBCs. The reaction between $\mathrm{Al}_{2} \mathrm{O}_{3}$ and new compositions such as pyrochlore $\mathrm{Gd}_{2} \mathrm{Zr}_{2} \mathrm{O}_{7}$ would form new interphases at a high temperature, decreasing the integrity of TBCs [14]. Cubic YSZ has lower thermal conductivity than tetragonal YSZ, whereas the mechanical property such as fracture toughness is inferior compared with that of tetragonal YSZ $[15,16]$. Tetragonal oxides have superior fracture toughness compared with cubic oxides as a result of two toughening mechanisms, ferroelastic toughening and transformation toughening [17]. The desirable phase composition for the commercial YSZ coatings is the $t^{\prime}$-tetragonal structure which has enhanced phase stability compared with the tetragonal structure $[18,19]$. The $t$ '-tetragonal structure could form the tweed microstructure which exhibited better thermo-mechanical properties due to structural toughening [20, 21]. 
MD simulation can be utilized to calculate the intrinsic thermodynamic properties of ionic oxide without the influence of microstructures. The thermal conductivity can be calculated using equilibrium MD simulation and non-equilibrium MD simulation methods [22]. The non-equilibrium MD simulation applies a temperature gradient on the simulation box, from which the thermal conductivity can be determined. The equilibrium MD simulation imposes heat current fluctuation across the simulation cell to compute thermal conductivity based on the fluctuation-dissipation theory. The advantages of the direct method over the equilibrium approach, include the fast convergence in the $(\mathrm{N}, \mathrm{P}, \mathrm{T})$-ensemble, the ability to model complex structures and the incorporation of anharmonic effects with further assumptions [23]. The thermal conductivity of pyrochlore oxides has been predicted by MD simulation, which shows great potential to analyse the effects of the composition and point-defect concentration $[24,25]$.

The aim of the present work is to synthesize new composition Dy $y_{0.06} \mathrm{Y}_{0.072} \mathrm{Zr}_{0.868} \mathrm{O}_{1.934}$ powders via a sol-gel processing route and to study the thermodynamic properties of pelletized powders via experimental approaches combined with the non-equilibrium MD simulation. Structural characterization has been conducted via a combination of scanning electron microscope (SEM), x-ray diffraction (XRD), Raman spectroscopy and neutron diffraction. Neutron diffraction is effective in studying crystal structure and is sensitive to light elements such as oxygen, because the neutron is scattered by the nuclei while the x-ray is diffracted by the electrons surrounding the nuclei [26]. The total scattering ratio of the $x-$ ray amount of oxygen and zirconium is $1: 25$, whereas the scattering ratio of the neutron power of oxygen and zirconium is 1:3.9 [27]. A sol-gel approach for powder mixing combined with high temperature calcination for the phase stability study have been utilized to investigate the thermochemical compatibility with $\mathrm{Al}_{2} \mathrm{O}_{3}$.

\section{Method}

\subsection{Experiment}

Dy ${ }_{0.06} \mathrm{Y}_{0.072} \mathrm{Zr}_{0.868} \mathrm{O}_{1.934}$ ceramic powders were prepared via an alkoxide based sol-gel method. The details of the sol-gel method have been described elsewhere [28]. The as-prepared powders were sintered at $1200^{\circ} \mathrm{C}$ for 2 hours, followed by uniaxial compaction of the powders into pellets and sintered at $1200^{\circ} \mathrm{C}$ for 6 hours. 
The thermodynamic stability between the as-synthesized powders and $\mathrm{Al}_{2} \mathrm{O}_{3}$ was studied via a viscous sol-gel method. The starting materials included ethylene glycol $(99.5 \%$, SigmaAldrich Company Ltd.) and aluminium nitrate nonahydrate (98\%, Sigma-Aldrich Company Ltd.). Aluminium nitrate nonahydrate was dissolved in deionized water followed by the addition of ethylene glycol into the water solution containing $\mathrm{Al}^{3+}$ cation under vigorous stirring.

The as-synthesized powders were mixed with the $\mathrm{Al}^{3+}$ precursor solution, followed by vigorous stirring for $30 \mathrm{~min}$. The solution was heated in a water bath to form the composite sol and dried at $120^{\circ} \mathrm{C}$ to form the composite xerogel. The composite gel was calcined at $900^{\circ} \mathrm{C}$ for 3 hours, followed by sintering between $1300^{\circ} \mathrm{C}$ and $1500^{\circ} \mathrm{C}$ for the thermochemical compatibility study.

The crystal structure of ceramic powders was characterized via XRD, using a Siemens D500 $\mathrm{x}$-ray diffractometer $(\mathrm{Cu}-\mathrm{K} \alpha$ radiation, $\lambda=1.54 \AA$ ) and neutron diffraction using a Wish instrument at ISIS in the UK [29]. The molecular symmetry was investigated by Raman spectroscopy using a Horiba Jobin-Yvon LabRAM spectrometer equipped with an Olympus BX41 microscope (He-Ne laser source, $632.8 \mathrm{~nm}$ ). The surface morphology and the microstructure of the particles were examined by a Phillips XL30 SEM. The thermal conductivity of the pellets was measured using a thermal conductivity analyser (C-Therm TCi) at room temperature. The coefficient of thermal expansion was measured via a NETZSCH DIL $402 \mathrm{C}$ dilatometer from room temperature to $1000^{\circ} \mathrm{C}$ with a heating rate of $5^{\circ} \mathrm{C} / \mathrm{min}$ under air atmosphere. The bulk density $\left(\rho_{1}\right)$ was determined by measuring the weight $(w)$ and the volume $(v)$ of the pellet directly, where $\rho_{1}=w / v$. The theoretical density $\rho_{t}$ was calculated via the lattice parameters from XRD and the molecular weight. The porosity was estimated from the ratio of the bulk density and the theoretical density $\left(\varphi=1-\rho_{1} / \rho_{t}\right)$. The bulk thermal conductivity was calculated based on the porosity and the measured thermal conductivity using,

$$
\kappa_{0}=\frac{1}{1-\frac{4}{3} \varphi} \kappa
$$

where $\varphi$ is the porosity, $\kappa$ is the measured thermal conductivity of porous materials and $\kappa_{0}$ is the corrected thermal conductivity for the dense material [30]. The correction of the thermal 
conductivity is based on assumptions that spherical pores incorporated into a homogeneous medium and the thermal conductivity for pores is infinite.

\subsection{MD simulation}

The MD simulation is based on a rigid-ion model via $6 \times 6 \times 32$ tetragonal unit cells [31]. In the simulation cell, $\mathrm{Y}^{3+}$ ions, $\mathrm{Zr}^{4+}$ ions and $\mathrm{Dy}^{3+}$ ions are randomly located in cation sites and $\mathrm{O}^{2-}$ ions are randomly located in anion sites. The starting positions are initialized in a tetragonal lattice with an initial displacement and the initial crystal structure information is taken from $\mathrm{XRD}$ results at room temperature. In the simulation, $5 \times 10^{4} \mathrm{MD}$ steps (25 ps) are carried out in the $(\mathrm{N}, \mathrm{P}, \mathrm{T})$-ensemble to equilibrate the system, and $2.5 \times 10^{5} \mathrm{MD}$ steps (125 ps) are carried out in the $(\mathrm{N}, \mathrm{V}, \mathrm{E})$-ensemble to calculate the thermodynamic properties.

The total forces between ions have been described via interatomic potentials in which a Buckingham potential is utilized for the short-range interaction between ions, and a Coulomb potential is applied for the long-range electrostatic effects [32].

$$
V_{i j}=A_{i j} \exp \left(\frac{-r_{i j}}{\rho_{i j}}\right)-\frac{C_{i j}}{r_{i j}^{6}}+\frac{Q_{i} Q_{j}}{4 \pi \varepsilon_{0} r_{i j}}
$$

where $V_{i j}$ is the potential energy between particles $i$ and $j$ associated with ionic charges $Q_{i}$ and $Q_{j}, A_{i j}, \rho_{i j}$ and $C_{i j}$ are Buckingham potential parameters, $r_{i j}$ is the separation of two particles, and $\varepsilon_{0}$ is the vacuum permittivity [31]. Short-range forces are calculated via the direct summation method where a cut-off radius is applied, and a long-range correction is added. The long-range forces are determined via the Wolf method [33, 34]. Short-range potential parameters for the simulation are presented in Table 1 and cation-cation short-range parameters are zero. The potential parameters for YSZ are derived by Schelling et al. to better describe the tetragonal and cubic phases [32]. The potential parameters for Dy-O are determined by Stanek et al. based on a multistructural fitting approach to reproduce the lattice parameters of pyrochlore structures [35].

\begin{tabular}{ccccc}
\hline Species & $A(\mathrm{eV})$ & $\rho(\AA)$ & $C\left(\mathrm{eV} \cdot \AA^{6}\right)$ & Ref \\
\hline $\mathrm{Y}^{3+}-\mathrm{O}^{2-}$ & 1366.35 & 0.348 & 19.6 & {$[31]$} \\
$\mathrm{Zr}^{4+}-\mathrm{O}^{2-}$ & 1502.11 & 0.345 & 5.1 & {$[31]$} \\
$\mathrm{O}^{2-}-\mathrm{O}^{2-}$ & 9547.96 & 0.224 & 32 & {$[31]$} \\
$\mathrm{Dy}^{3+}-\mathrm{O}^{2-}$ & 1807.84 & 0.3393 & 18.77 & {$[35]$} \\
\hline
\end{tabular}

Table 1. Potential energy parameters of the short-range forces 
The non-equilibrium MD simulation is used to calculate the thermal conductivity from the $(\mathrm{N}$, $\mathrm{V}, \mathrm{E}$ )-ensemble. The heat is added into a slab of materials and an equal amount of heat is removed from another slab of materials in every time step, creating a temperature gradient along the long dimension of the simulation cell, as depicted in Figure 1. A thermal plate power $\left(\frac{\Delta \varepsilon}{\Delta t}\right)$ of $320 \mathrm{nW}$ is incorporated into the system with a MD time step of 0.5 fs for the calculation of the heat current along z-direction. Modified velocity rescaling algorithms developed by Jund and Jullien, are used to apply and remove the constant energy $\Delta \varepsilon$ [36]. To avoid the kinetic energy drift, the total momentum inside the 'cold' and 'hot' slices needs to be conserved. The temperature is determined from the kinetic energy and is averaged over the $(\mathrm{N}, \mathrm{V}, \mathrm{E})$-ensemble. Thus, the thermal conductivity can be computed via Fourier's law of heat conduction,

$$
J_{z}=-\kappa \frac{d T}{d Z}
$$

where $\kappa$ is the thermal conductivity, $\frac{d T}{d Z}$ is the temperature gradient along z-direction and $J_{z}$ is the heat current [22].

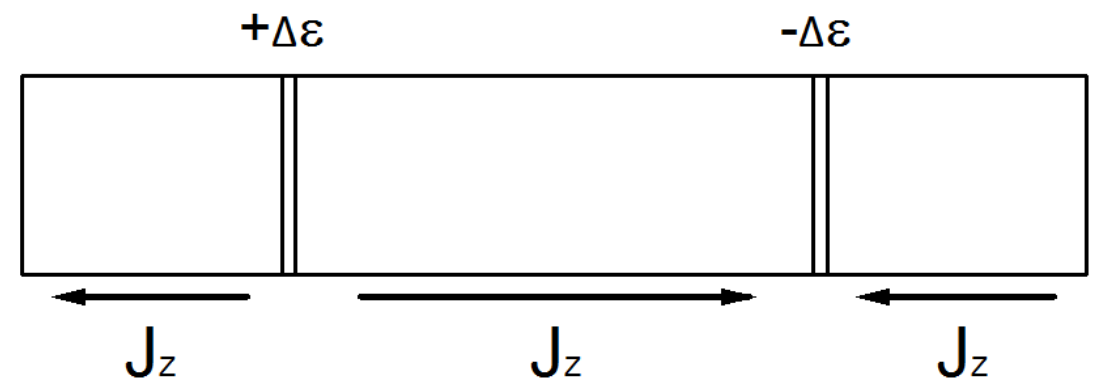

Figure 1. Schematic diagram of the heat conduction in a periodic simulation box ( $\Delta \varepsilon$ is the heat incorporated and removed from two slabs)

\section{Results and Discussion}

\subsection{Characterization}

\section{a) SEM}

The morphology and microstructure of calcined ceramic powders were characterized via SEM, as presented in Figure 2. The particle shape of $\mathrm{Dy}_{0.06} \mathrm{Y}_{0.072} \mathrm{Zr}_{0.868} \mathrm{O}_{1.934}$ is similar to that of 4YSZ, exhibiting irregular morphology with sharp edges. The particle size, estimated 
using the ImageJ software, is $13.121 \pm 1.218 \mu \mathrm{m}$ for $\mathrm{Dy}_{0.06} \mathrm{Y}_{0.072} \mathrm{Zr}_{0.868} \mathrm{O}_{1.934}$ particles and is $13.742 \pm 1.057 \mu \mathrm{m}$ for 4 YSZ particles.

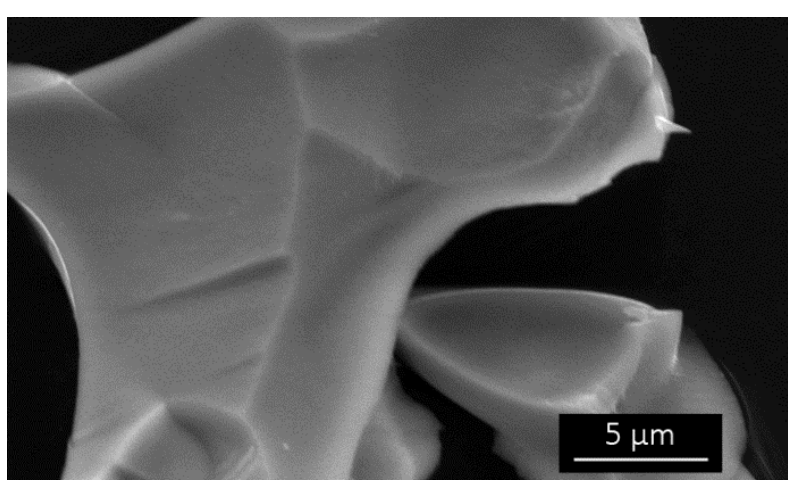

(a)

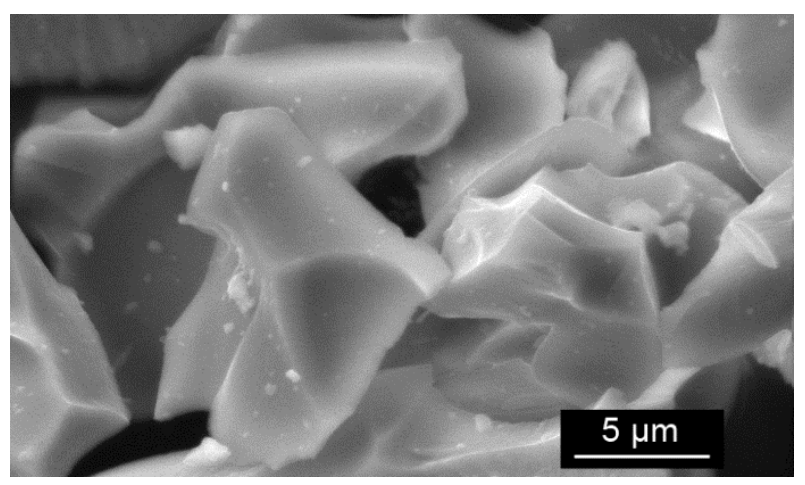

(b)

Figure 2. SEM images of the surface morphology of: (a) 4YSZ particles; (b) Dy ${ }_{0.06} \mathrm{Y}_{0.072} \mathrm{Zr}_{0.868} \mathrm{O}_{1.934}$ particles

\section{b) XRD}

Figure 3(a) shows phase compositions of $\mathrm{Dy}_{0.06} \mathrm{Y}_{0.072} \mathrm{Zr}_{0.868} \mathrm{O}_{1.934}$ and 4YSZ which consist of the t'-tetragonal and tetragonal structure, respectively. The tetragonal peaks of $\mathrm{Dy}_{0.06} \mathrm{Y}_{0.072} \mathrm{Zr}_{0.868} \mathrm{O}_{1.934}$ powders shift slightly to lower diffraction angles, owing to the incorporation of $6 \mathrm{~mol} \% \mathrm{Dy}^{3+}$ ions into the $\mathrm{ZrO}_{2}$ lattice. This could enhance the lattice constant, resulting in a smaller diffraction $2 \theta$ angle. Slow-scan XRD patterns from 71 to $77^{\circ}$ $2 \theta$ angle are presented in Figure 3(b) and (c). The peak splitting level of Dy ${ }_{0.06} \mathrm{Y}_{0.072} \mathrm{Zr}_{0.868} \mathrm{O}_{1.934}$ decreases, as compared with that of $4 \mathrm{YSZ}$, accompanied by the decrease of the tetragonality $(c / \sqrt{2} a)$. 


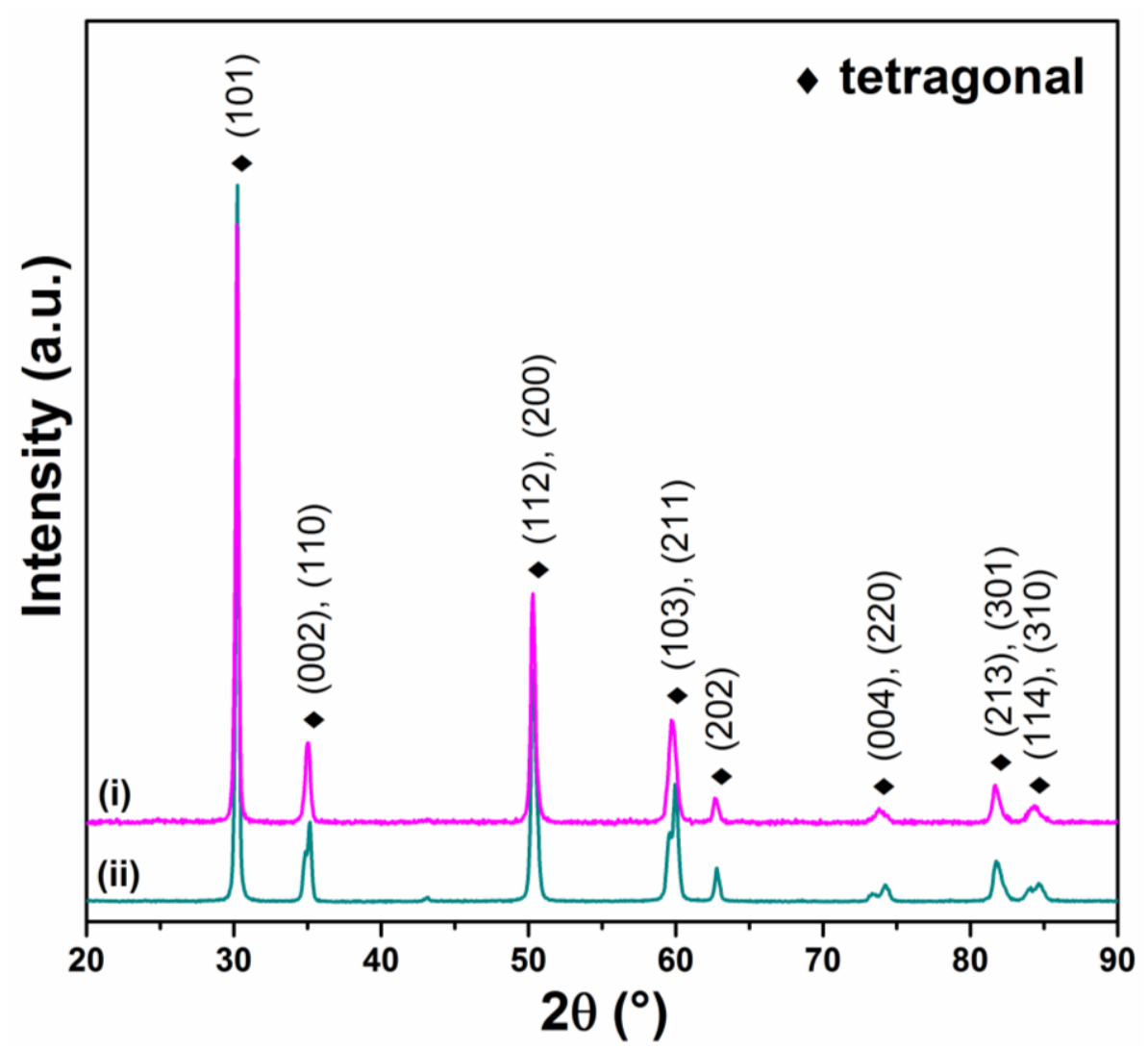

(a)

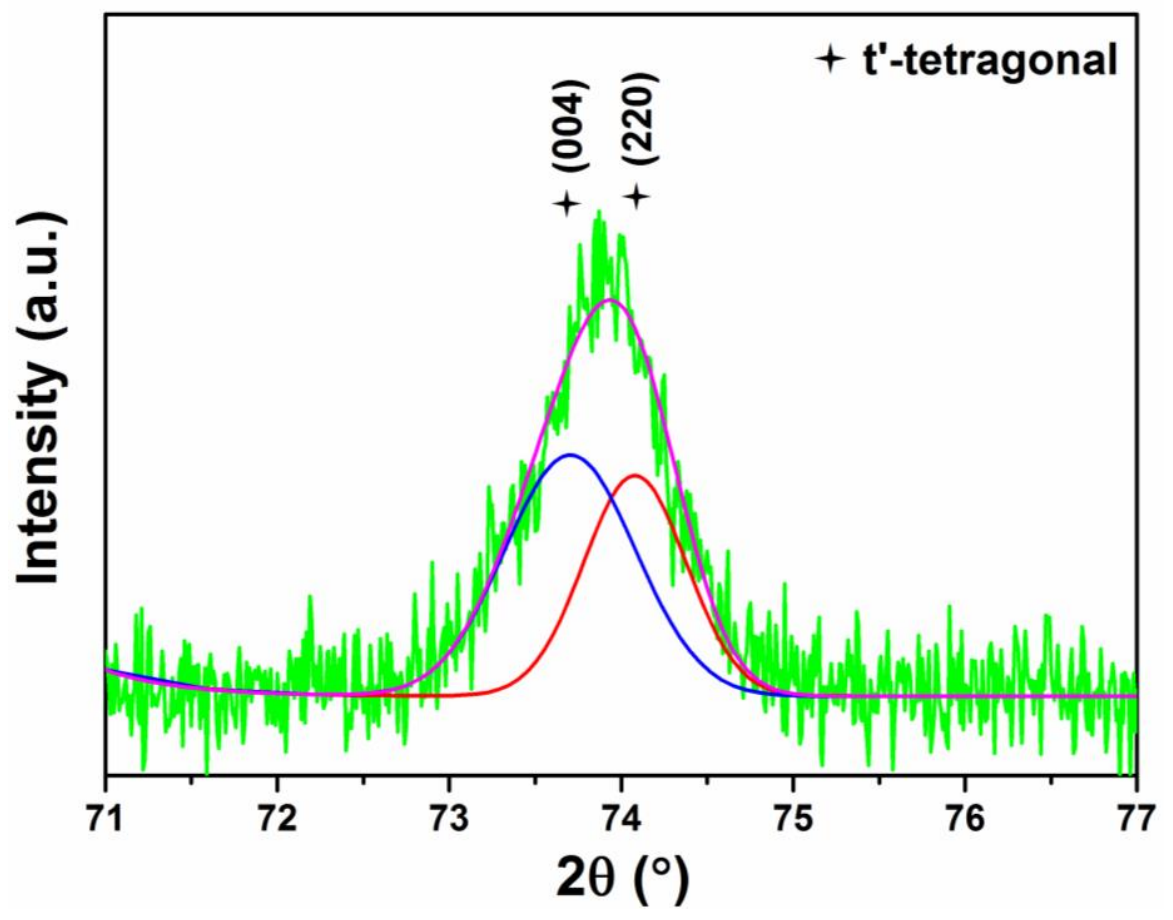

(b) 


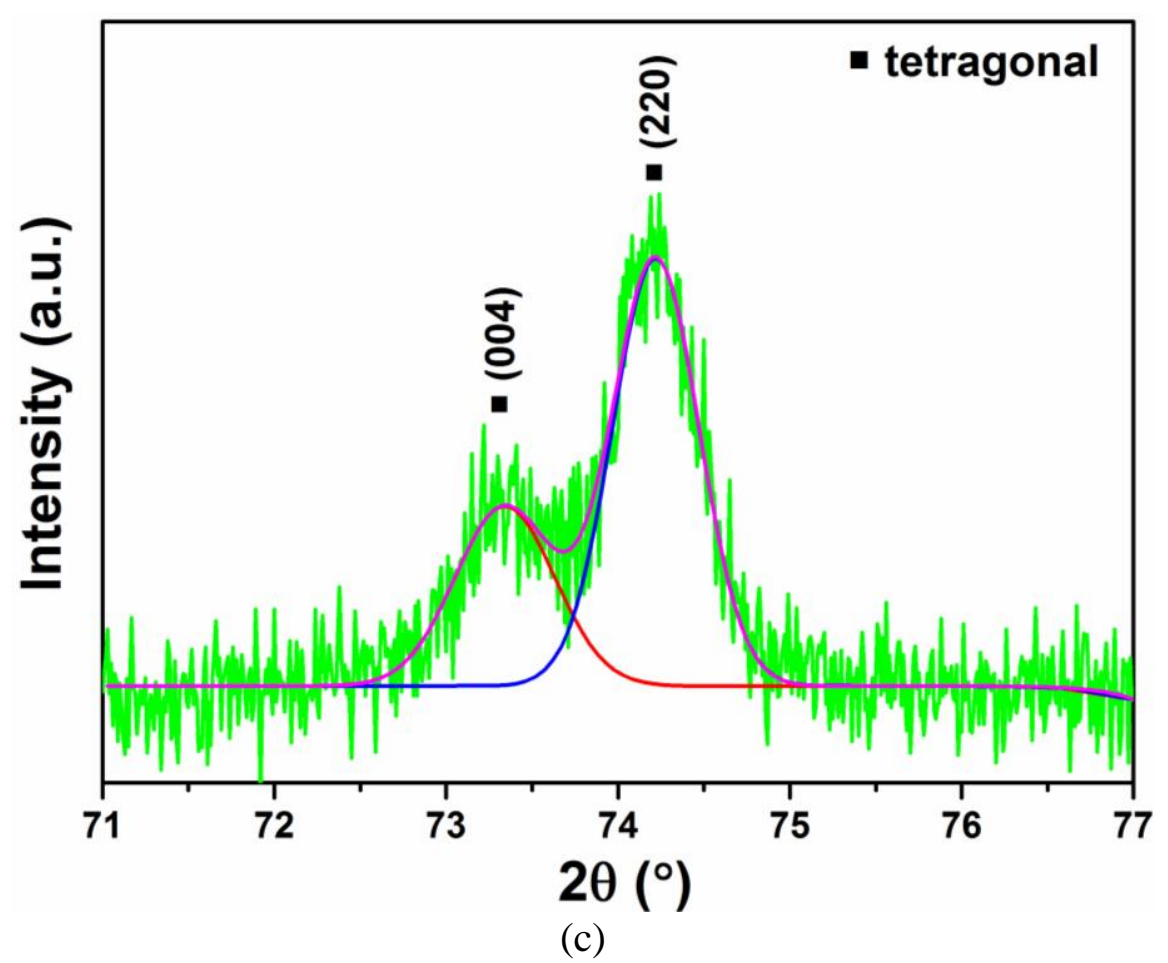

Figure 3. (a) XRD patterns of: (i) $\mathrm{Dy}_{0.06} \mathrm{Y}_{0.072} \mathrm{Zr}_{0.868} \mathrm{O}_{1.934}$ powders; (ii) 4YSZ powders; (b) a slow-scan XRD pattern of Dy ${ }_{0.06} \mathrm{Y}_{0.072} \mathrm{Zr}_{0.868} \mathrm{O}_{1.934}$ powders; (c) a slow-scan XRD pattern of 4YSZ powders

Moreover, the crystal size was estimated via the line broadening using the Scherrer equation, as presented in Figure 4. The crystal size of $\mathrm{Dy}_{0.06} \mathrm{Y}_{0.072} \mathrm{Zr}_{0.868} \mathrm{O}_{1.934}$ powders is similar to that of $4 \mathrm{YSZ}$ powders when sintered at $950^{\circ} \mathrm{C}$, whereas the crystal size of $\mathrm{Dy}_{0.06} \mathrm{Y}_{0.072} \mathrm{Zr}_{0.868} \mathrm{O}_{1.934}$ powders is lower, compared with that of $4 \mathrm{YSZ}$ due to the calcination at $1200^{\circ} \mathrm{C}$. Therefore, this suggests that the addition of $\mathrm{Dy}^{3+}$ is effective in limiting the grain growth during the heat treatment at $1200^{\circ} \mathrm{C}$. 


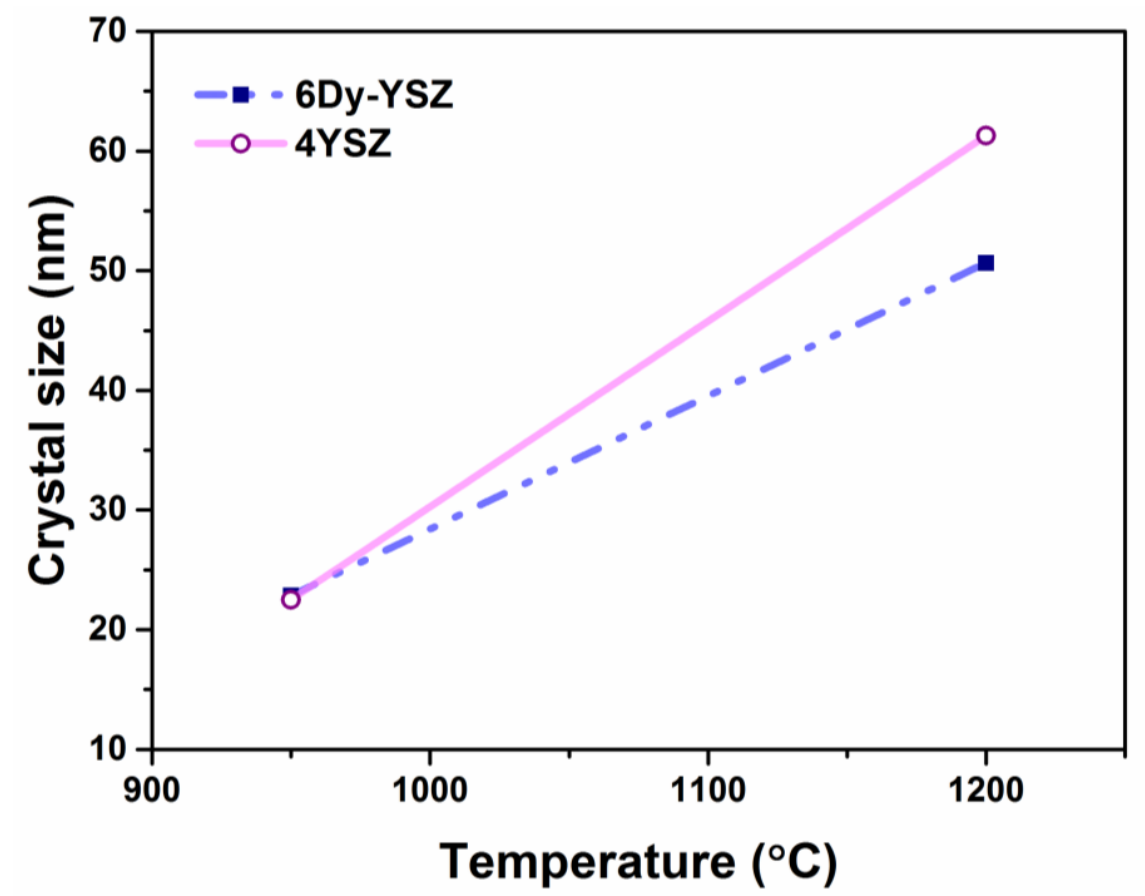

Figure 4. The estimated crystal size of powders sintered at $950^{\circ} \mathrm{C}$ for 3 hours and at $1200^{\circ} \mathrm{C}$ for 2 hours

\section{c) Neutron diffraction}

Neutron diffraction is a complementary technique to XRD with respect to structural characterization, as the penetration depth of the neutron is larger than that of x-ray and can be utilized to study magnetic structure [37]. Neutron diffraction combined with the Rietveld refinement was conducted to verify the phase composition of $\mathrm{Dy}_{0.06} \mathrm{Y}_{0.072} \mathrm{Zr}_{0.868} \mathrm{O}_{1.934}$ powders, as presented in Figure 5. The observed data and the calculated data are in good agreement, and the difference mainly results from the intensity and the curvature of the diffraction peaks. The diffraction peaks of $\mathrm{Dy}_{0.06} \mathrm{Y}_{0.072} \mathrm{Zr}_{0.868} \mathrm{O}_{1.934}$ correspond to the tetragonal structure $(P 42 / n$ $m c$ ). The fitness factors for the Rietveld refinement are listed in Table 2. 


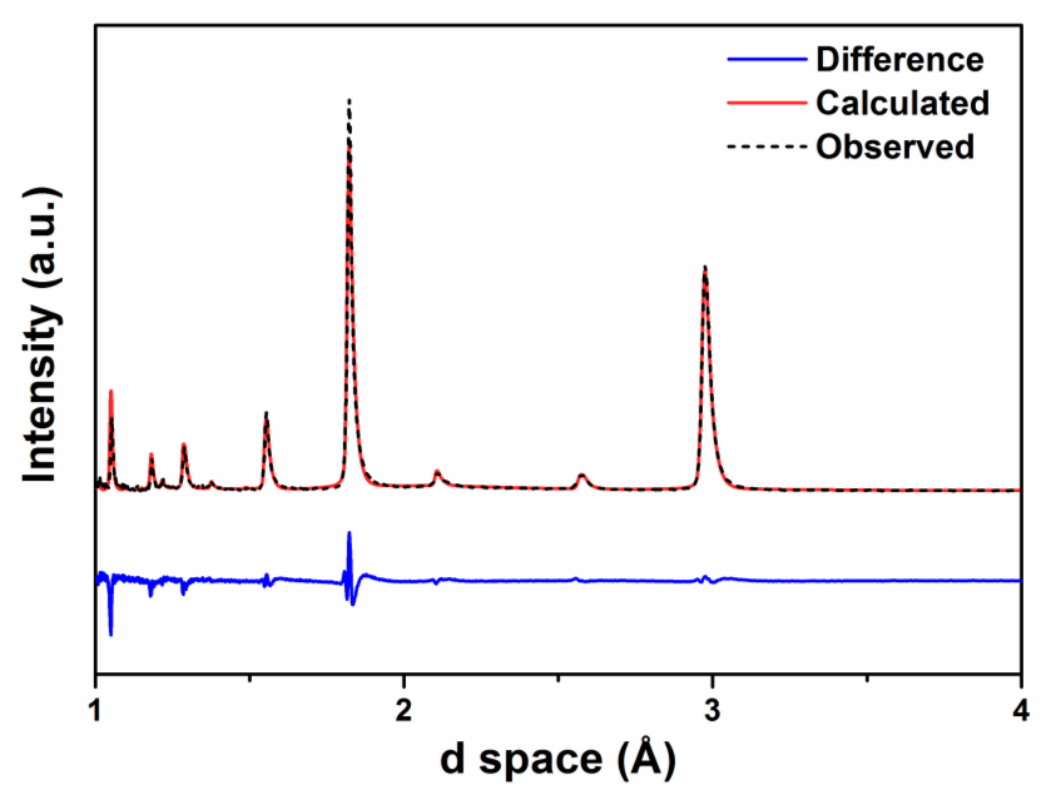

Figure 5. Neutron diffraction patterns of $\mathrm{Dy}_{0.06} \mathrm{Y}_{0.072} \mathrm{Zr}_{0.868} \mathrm{O}_{1.934}$ powders

\begin{tabular}{ll}
\hline & $\mathrm{Dy}_{0.06} \mathrm{Y}_{0.072} \mathrm{Zr}_{0.868} \mathrm{O}_{1.934}$ \\
\hline $\mathrm{R}_{\mathrm{p}}$ & 0.0625 \\
$\mathrm{R}_{\mathrm{wp}}$ & 0.0577 \\
Goodness of fit & 2.98 \\
\hline
\end{tabular}

Table 2. Fitness factors of the refinement

The lattice structure studied via the neutron diffraction agrees well with the lattice parameters of Dy $y_{0.06} \mathrm{Y}_{0.072} \mathrm{Zr}_{0.868} \mathrm{O}_{1.934}$ powders determined from MD simulation with a relative difference of $0.02 \%$ and $0.5 \%$ for $a$ and $c$, respectively (Table 3). The tetragonality of Dy ${ }_{0.06} \mathrm{Y}_{0.072} \mathrm{Zr}_{0.868} \mathrm{O}_{1.934}$ calculated via the MD simulation slightly decreases compared with that of the experimental results. Moreover, $c / \sqrt{2} a$ is 1.0054 for $\mathrm{Dy}_{0.06} \mathrm{Y}_{0.072} \mathrm{Zr}_{0.868} \mathrm{O}_{1.934}$ from neutron diffraction, further confirming that the crystal structure is t'-tetragonal with the incorporation of the $6 \mathrm{~mol} \% \mathrm{Dy}^{3+}$ ions [38].

\begin{tabular}{lcccc}
\hline & $a(\AA)$ & $b(\AA)$ & $c(\AA)$ & $\alpha=\beta=\gamma$ \\
\hline Neutron diffraction & 3.628965 & 3.628965 & 5.158960 & $90^{\circ}$ \\
MD simulation & 3.629803 & 3.629803 & 5.133016 & $90^{\circ}$ \\
\hline
\end{tabular}

Table 3. Lattice constant of $\mathrm{Dy}_{0.06} \mathrm{Y}_{0.072} \mathrm{Zr}_{0.868} \mathrm{O}_{1.934}$ determined via neutron diffraction and MD simulation at $300 \mathrm{~K}$ 


\section{d) Raman Analysis}

The Raman spectra represent the vibrational modes of a tetragonal structure, as presented in Figure 6. Five active vibration modes are identified for $\mathrm{Dy}_{0.06} \mathrm{Y}_{0.072} \mathrm{Zr}_{0.868} \mathrm{O}_{1.934}$, including the $E_{\mathrm{g}}$ stretching mode at $257 \mathrm{~cm}^{-1}$, the $\mathrm{Zr}-\mathrm{O} \mathrm{B}_{1 \mathrm{~g}}$ bending mode at $324 \mathrm{~cm}^{-1}$, the $\mathrm{Zr}-\mathrm{O}$ stretching $\mathrm{E}_{\mathrm{g}}$ mode at $464 \mathrm{~cm}^{-1}$, the symmetric $\mathrm{O}-\mathrm{Zr}-\mathrm{O} \mathrm{A}_{1 \mathrm{~g}}$ stretching mode at $615 \mathrm{~cm}^{-1}$ and the asymmetric O-Zr-O E $\mathrm{g}$ stretching mode at $638 \mathrm{~cm}^{-1}$ [39]. As can be seen, the incorporation of $6 \mathrm{~mol}^{2} \mathrm{Dy}^{3+}$ ions results in the red shift of the vibrational modes, particularly for the symmetric O-Zr-O A $\mathrm{A}_{\mathrm{g}}$ stretching mode, from $620 \mathrm{~cm}^{-1}$ to $615 \mathrm{~cm}^{-1}$. The addition of $\mathrm{Dy}^{3+}$ ions to $\mathrm{ZrO}_{2}$ can bring about the bond elongation and weakening, by which the Raman bands shift towards low frequencies [40].

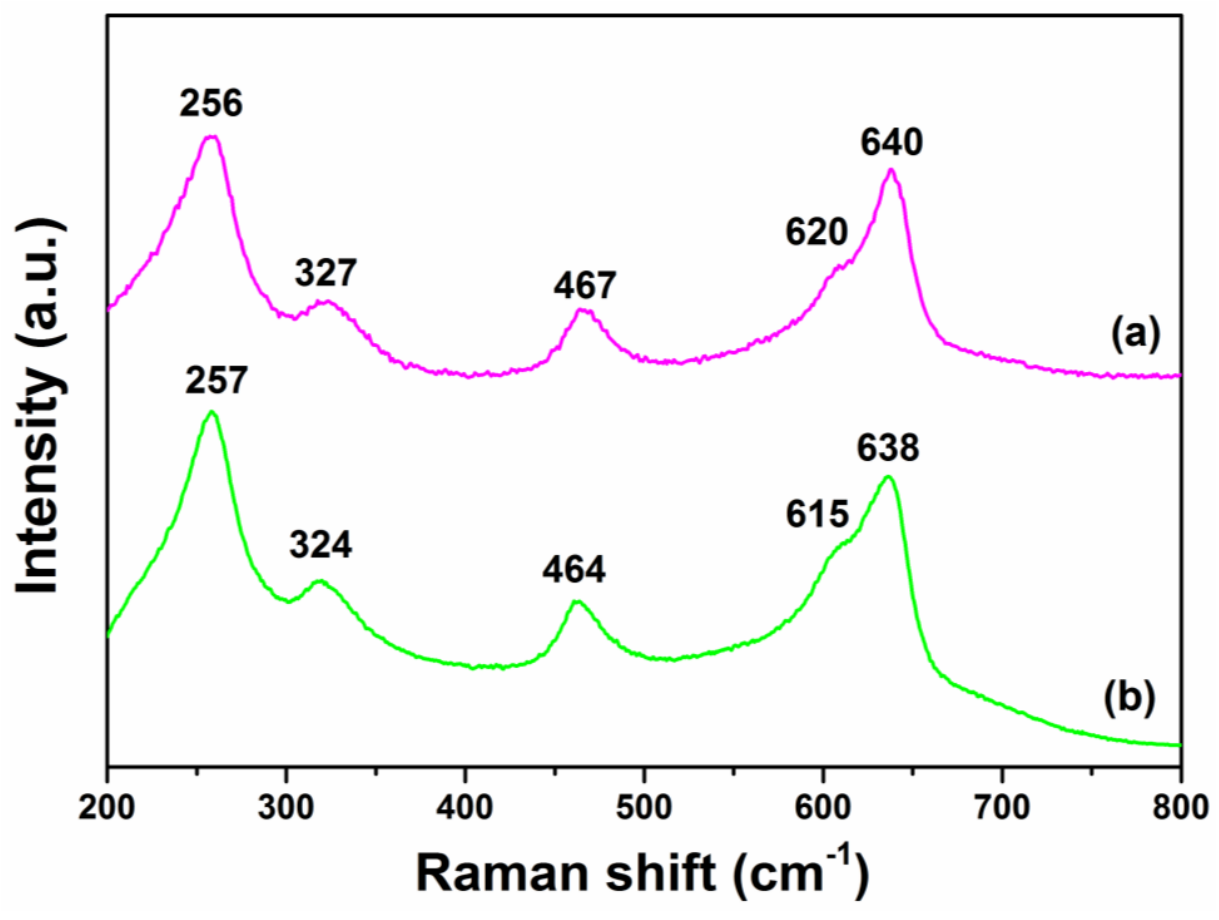

Figure 6. Raman spectra of: (a) 4YSZ; (b) Dy $\mathrm{y}_{0.06} \mathrm{Y}_{0.072} \mathrm{Zr}_{0.868} \mathrm{O}_{1.934}$

The Raman shift intensity ratio of $\mathrm{I}_{4} / \mathrm{I}_{6}$ where $\mathrm{I}_{4}$ represents $\mathrm{Zr}-\mathrm{O}$ stretching $\mathrm{E}_{\mathrm{g}}$ mode and $\mathrm{I}_{6}$ corresponds to the asymmetric $\mathrm{O}-\mathrm{Zr}-\mathrm{O} \mathrm{E}_{\mathrm{g}}$ stretching mode, can be calculated so as to determine the oxygen displacement in the tetragonal lattice (Table 4) [19]. The incorporation of $6 \mathrm{~mol} \% \mathrm{Dy}^{3+}$ ions decreases the $\mathrm{I}_{4} / \mathrm{I}_{6}$ ratio, therefore indicating that the oxygen displacement decreases. This can be the result of the creation of oxygen vacancies owing to the substitution of $\mathrm{Zr}^{4+}$ by $\mathrm{Dy}^{3+}$ ions, which promotes the formation of the cubic structure. 


\begin{tabular}{lll}
\hline & $4 \mathrm{YSZ}$ & $\mathrm{Dy}_{0.06} \mathrm{Y}_{0.072} \mathrm{Zr}_{0.868} \mathrm{O}_{1.934}$ \\
\hline $\mathrm{I}_{4} / \mathrm{I}_{6}$ & 0.4071 & 0.3724 \\
\hline
\end{tabular}

Table 4. Raman shift intensity ratio of $\mathrm{I}_{4} / \mathrm{I}_{6}$

\subsection{Measured Thermal Conductivity}

The thermal conductivity of ceramic materials is controlled by composition and microstructure. Modifying the chemical composition can lower the thermal conductivity, and it can be further decreased via optimizing the microstructure. The thermal conductivity was measured at room temperature based on the modified transient plane source (MTPS) method and was corrected to that of a dense sample using Equation (1), as presented in Table 5. In the MTPS method, an interfacial sensor is used to heat the sample and measure the temperature change simultaneously [41]. The time-dependent voltage change is directly proportional to $\sqrt{t}$, from which the effusivity is determined,

$$
e=\sqrt{\kappa \cdot \rho \cdot C}
$$

where $e$ is the effusivity, $\kappa$ is the thermal conductivity, $\rho$ is the density and $C$ is the specific heat capacity [41]. Moreover, $\kappa_{\min }$ has been estimated based on Clarke's equation with the assumption of the minimum mean free path, mean phonon velocity and Debye's model for thermal conductivity [42].

$$
\kappa_{\min }=0.87 k_{B} N_{A}^{\frac{2}{3}} \frac{m^{\frac{2}{3}} \rho^{\frac{1}{6}} E^{\frac{1}{2}}}{M^{\frac{2}{3}}}
$$

where $E$ is the Young's modulus, $M$ is the molecular weight, $m$ is the number of atoms per molecular formula, $k_{B}$ is Boltzmann's constant and $N_{A}$ is the Avogadro's number [43]. The bulk modulus was determined from,

$$
\alpha=\frac{\gamma \rho C_{P}}{3 B_{m}}
$$

where $\alpha$ is the coefficient of thermal expansion, $C_{P}$ is the isobaric heat capacity, $\rho$ is the density, $B_{m}$ is the bulk modulus and $\gamma$ is the Grüneisen constant [44-46]. Young's modulus was estimated via the bulk modulus and the Poisson's ratio [47]. The Poisson's ratio, $v$, and Grüneisen parameter, $\gamma$, were assumed to be the same as those of 4YSZ $(v=0.2, \gamma=1.40)$ [4850]. The assumption of the Grüneisen parameter would undermine the influence of the lattice 
vibration anharmonicity [30]. However, the Grüneisen parameter is reported to change slowly attributed to the chemical composition variation [46]. The composition difference can influence the density, specific heat, lattice constants and oxygen vacancy concentration, which are critical to the thermal conductivity. Poisson's ratio is influenced by the microstructure which is assumed to be similar for the bulk samples [50]. Table 5 shows that the calculated $\kappa_{\min }$ agrees well with the trend of experimental values.

Varying the chemical composition by the incorporation of $\mathrm{Dy}^{3+}$ ions decreases the thermal conductivity of 4YSZ due to the mass difference and the ionic radii misfit between doping cations and $\mathrm{Zr}^{4+}$ ions, and the creation of oxygen vacancies. Furthermore, the crystal size of Dy0.06 $\mathrm{Y}_{0.072} \mathrm{Zr}_{0.868} \mathrm{O}_{1.934}$ is smaller than that of $4 \mathrm{YSZ}$ after the calcination at $1200^{\circ} \mathrm{C}$, thus providing more boundaries to scatter phonons and to decrease the phonon mean free path. Moreover, $\kappa_{\min }$ has been estimated from the measurement of the thermal conductivity, coefficient of thermal expansion and density, which agrees well with the trend of experimental values.

\begin{tabular}{lll}
\hline & $4 \mathrm{YSZ}$ & $\mathrm{Dy}_{0.06} \mathrm{Y}_{0.072} \mathrm{Zr}_{0.868} \mathrm{O}_{1.934}$ \\
\hline Thermal conductivity $(\mathrm{W} / \mathrm{m} \cdot \mathrm{K})$ & $2.3517 \pm 0.2610$ & $2.1869 \pm 0.3337$ \\
Coefficient of thermal expansion & 11.3932 & 11.8070 \\
$\left(\times 10^{-6} \mathrm{~K}^{-1}\right)$ & & \\
Specific heat capacity $(\mathrm{J} / \mathrm{kg} \cdot \mathrm{K})$ & 329.24 & 330.05 \\
Density $\left(\mathrm{g} / \mathrm{cm}^{3}\right)$ & 6.0339 & 6.1955 \\
$\kappa_{\min }(\mathrm{W} / \mathrm{m} \cdot \mathrm{K})$ & 1.1698 & 1.1400 \\
\hline
\end{tabular}

Table 5. Thermal conductivity corrected to dense samples

Additionally, the key to decrease the phonon mean free path is to enhance the phonon scattering process, including both Umklapp phonon-phonon and phonon-defect scattering. Umklapp phonon-phonon scattering is a temperature-dependent process and becomes dominated by the increase in temperature, whereas phonon-defect scattering process is a temperature-independent process [49]. The phonon-defect scattering coefficient can be calculated by,

$$
\Gamma=\sum x_{i}\left[\left(\frac{\Delta M_{i}}{M}\right)^{2}+\varepsilon\left(\frac{\Delta \delta_{i}}{\delta}\right)^{2}\right]=\Gamma_{M}+\varepsilon \times \Gamma_{\delta}
$$


where $\Gamma$ is the scattering coefficient, $\Gamma_{M}$ is the defect scattering coefficient attributed to the mass misfit, $\Gamma_{\delta}$ is defect scattering coefficient due to the radius misfit, $x_{i}$ is the concentration, $M_{i}$ is the mass, $\delta_{i}$ is the ionic radius of component $i, M$ and $\delta$ are the mass and radius of the substituted site in the lattice, and $\varepsilon$ is the strain field factor,

$$
\varepsilon=\frac{2}{9}\left(6.4 \times \gamma \times \frac{1+v}{1-v}\right)^{2}
$$

where $\gamma$ is the Grüneisen parameter and $v$ is Poisson's ratio [45]. The scattering coefficient is calculated, in which the Poisson's ratio and Grüneisen parameter are assumed to be the same with those of 8 wt.\% YSZ. This assumption could underestimate the influence of the anharmonicity of the lattice vibration. This can be explained by the fact that the lattice disorder would increase with the increase of the doping level, resulting in the increase of the Grüneisen parameter. However, the assumption can still reflect the trend of the scattering coefficient due to composition variation because the Poisson's ratio and Grüneisen parameter only determine the magnification of the scattering coefficient from the radius misfit. Table 6 lists the scattering coefficient which suggests that the addition of $\mathrm{Dy}^{3+}$ ions can increase the phonon-defect scattering process. This also corresponds well with the decrease of the thermal conductivity due to doping effects.

\begin{tabular}{lcccc}
\hline & $\Gamma_{M}$ & $\Gamma_{\delta}$ & $\varepsilon$ & $\Gamma$ \\
\hline 4YSZ & 0.073 & 0.018 & 40 & 0.78 \\
Dy0.06 $\mathrm{Y}_{0.072} \mathrm{Zr}_{0.868} \mathrm{O}_{1.934}$ & 0.18 & 1.21 & 40 & 1.39 \\
\hline
\end{tabular}

Table 6. The phonon-defect scattering coefficient

\subsection{Non-equilibrium MD Simulation}

The internal energy of $4 \mathrm{YSZ}$ at $295 \mathrm{~K}$ is $-108.08 \mathrm{eV}$ per unit cell which is in agreement with the published value of $\mathrm{t}-\mathrm{ZrO}_{2}(-109.78 \mathrm{eV})$ [51]. The internal energy per chemical formula of $\mathrm{Dy}_{0.06} \mathrm{Y}_{0.072} \mathrm{Zr}_{0.868} \mathrm{O}_{1.934}$ becomes less negative than that of $4 \mathrm{YSZ}$, as presented in Figure 7 . Doping $6 \mathrm{~mol} \% \mathrm{Dy}^{3+}$ ions into YSZ enhances the internal energy by $2.25 \%$. 


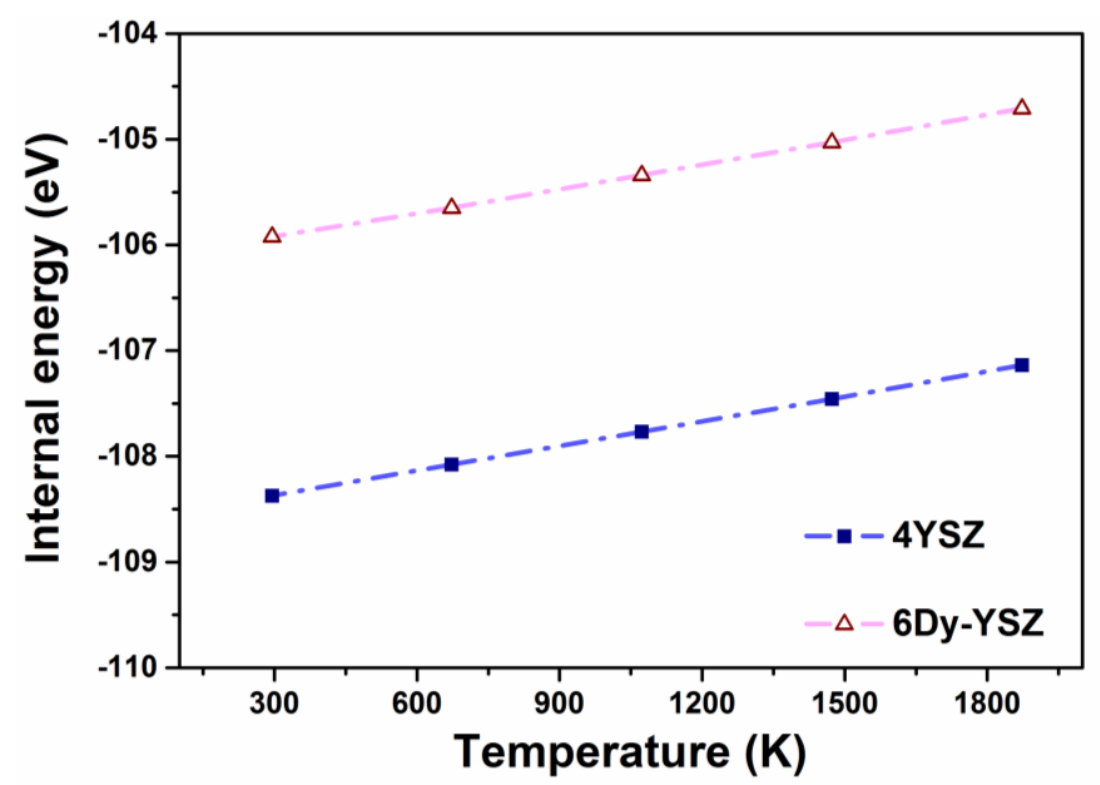

Figure 7. Internal energy from $295 \mathrm{~K}$ to $1873 \mathrm{~K}$ of: (a) $\mathrm{Dy}_{0.06} \mathrm{Y}_{0.072} \mathrm{Zr}_{0.868} \mathrm{O}_{1.934}$; (b) $4 \mathrm{YSZ}$

The thermal conductivity was calculated using the non-equilibrium MD simulation from 295 $\mathrm{K}$ to $1873 \mathrm{~K}$, as shown in Figure 8. The error bars were estimated by the temperature gradient from different parts of the temperature profile of the simulation cell at each temperature. The calculated thermal conductivity of $\mathrm{Dy}_{0.06} \mathrm{Y}_{0.072} \mathrm{Zr}_{0.868} \mathrm{O}_{1.934}$ is lower than that of $4 \mathrm{YSZ}$. Doping $\mathrm{Dy}^{3+}$ to $4 \mathrm{YSZ}$ can lower the theoretical thermal conductivity at $295 \mathrm{~K}$, which agrees well with the experimental measurement. Furthermore, at high temperatures, phonon-defect scattering is less important as compared with the phonon-phonon process [45]. The thermal conductivity decreases with the increase in temperature, due to the enhanced lattice vibration which can increase the phonon scattering process. The lattice thermal conductivity of $\mathrm{Dy}_{0.06} \mathrm{Y}_{0.072} \mathrm{Zr}_{0.868} \mathrm{O}_{1.934}$ at $1873 \mathrm{~K}$ is lower than that of $4 \mathrm{YSZ}$ by $30 \%$ attributed to the increased phonon-phonon scattering. 


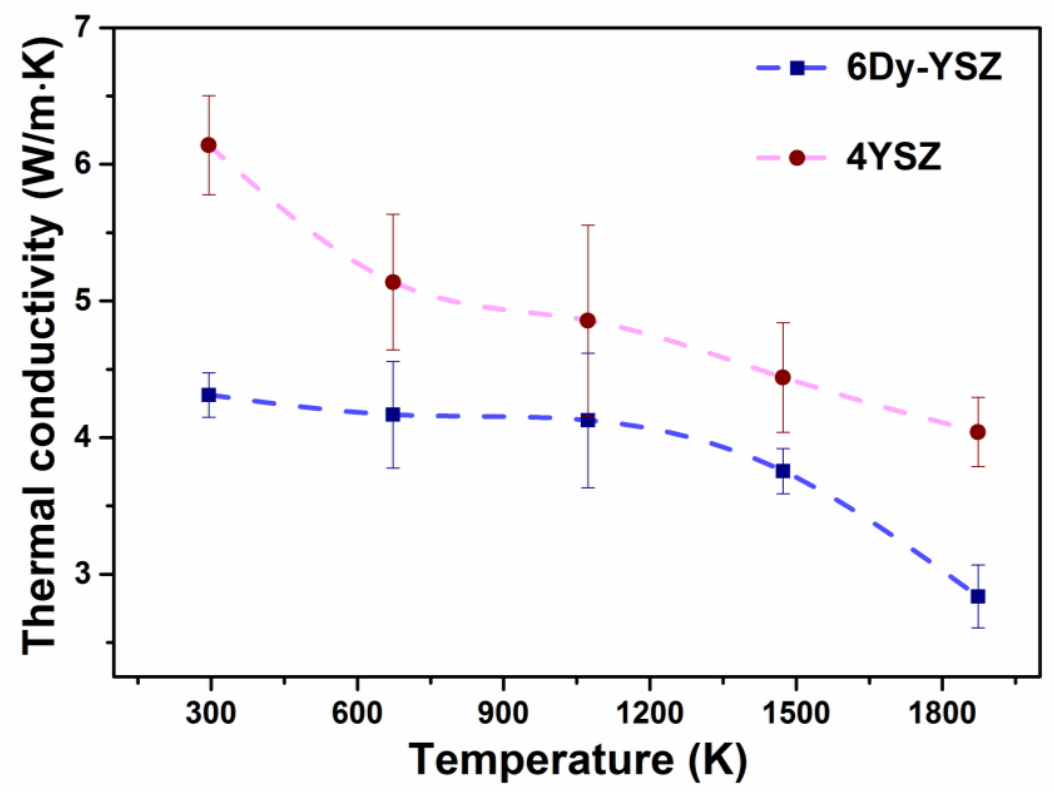

Figure 8 . Thermal conductivity calculated via MD simulation

The difference in the thermal conductivity between the experiment and MD simulation can in part be due to the influence of the microstructure such as the grain boundary, micro-cracks, defect clusters, interfaces between dissimilar phases and nano-pores [43, 52, 53]. Such microstructures enhance the phonon scattering process, whereas in the MD model, a single crystal is applied. On the other hand, the theoretically calculated thermal conductivity of $\mathrm{Dy}_{0.06} \mathrm{Y}_{0.072} \mathrm{Zr}_{0.868} \mathrm{O}_{1.934}$ and $4 \mathrm{YSZ}$ exhibits a larger difference than that measured in the experiment. Thus, the computation of the lattice thermal conductivity contributes to an effective selection approach of novel low-thermal-conductivity materials.

The details of the electronic structure of particles are ignored in MD simulation, which can influence the predicted dynamic property at low temperatures [54]. The model of doped $\mathrm{ZrO}_{2}$ is reported to include the high speed of sound and high-frequency vibrational modes at low temperatures [31]. This can in part contribute to a relatively high thermal conductivity. Furthermore, the thermal conductivity can be influenced by the length of the simulation cell $\mathrm{L}_{\mathrm{Z}}$, and $\frac{1}{\mathrm{l}_{\mathrm{eff}}}$ is proportional to $\left(\frac{1}{\mathrm{l}_{\infty}}+\frac{4}{\mathrm{~L}_{\mathrm{Z}}}\right)$ where $\mathrm{l}_{\infty}$ is the phonon mean free path of an infinite system and $\mathrm{l}_{\text {eff }}$ is the effective mean free path [22]. Dy0.06 $\mathrm{Y}_{0.072} \mathrm{Zr}_{0.868} \mathrm{O}_{1.934}$ which has a lower thermal conductivity than 4YSZ, results from a smaller mean free path. In this case, the same length of the simulation cell for $\mathrm{Dy}_{0.06} \mathrm{Y}_{0.072} \mathrm{Zr}_{0.868} \mathrm{O}_{1.934}$ and $4 \mathrm{YSZ}$ could influence the calculated thermal conductivity of 4 YSZ. 


\subsection{Measured Coefficient of Thermal Expansion}

The coefficient of thermal expansion for $4 \mathrm{YSZ}$ and $\mathrm{Dy}_{0.06} \mathrm{Y}_{0.072} \mathrm{Zr}_{0.868} \mathrm{O}_{1.934}$ was measured from room temperature to $1000^{\circ} \mathrm{C}$, as presented in Figure 9. The coefficient of thermal expansion for each composition is an average of 2 times' measurements, and the error is estimated within 5\%. The error bars are not presented for clarity. The coefficient of thermal expansion of $\mathrm{Dy}_{0.06} \mathrm{Y}_{0.072} \mathrm{Zr}_{0.868} \mathrm{O}_{1.934}$ is higher than that of $4 \mathrm{YSZ}$ from $600^{\circ} \mathrm{C}$ onwards.

The enhancement of the coefficient of thermal expansion of $\mathrm{Dy}_{0.06} \mathrm{Y}_{0.072} \mathrm{Zr}_{0.868} \mathrm{O}_{1.934}$ as compared with that of 4YSZ can be explained by the bonding energy of Dy-O $(615 \mathrm{~kJ} / \mathrm{mol})$ which is lower than that of $\mathrm{Zr}-\mathrm{O}(766.1 \mathrm{~kJ} / \mathrm{mol})$ [55]. The ionic radius of $\mathrm{Dy}^{3+}(1.03 \AA$, $\mathrm{CN}=8)$ is larger than that of $\mathrm{Zr}^{4+}(0.84 \AA, \mathrm{CN}=8)$, and the radius misfit leads to larger lattice distortion and increases the coefficient of thermal expansion. The addition of every two Dy ${ }^{3+}$ ions to substitute two $\mathrm{Zr}^{4+}$ ions creates one oxygen vacancy to balance the charge neutrality. The formation of the oxygen vacancy can weaken the bonding energy, which can also enhance the lattice dilation with the increase in temperature. Furthermore, it is reported that the coefficient of thermal expansion can be controlled by lattice energy variation [56]. The internal energy of $\mathrm{Dy}_{0.06} \mathrm{Y}_{0.072} \mathrm{Zr}_{0.868} \mathrm{O}_{1.934}$ is less negative than that of $4 \mathrm{YSZ}$, which could be utilized to explain the coefficient of thermal expansion variation.

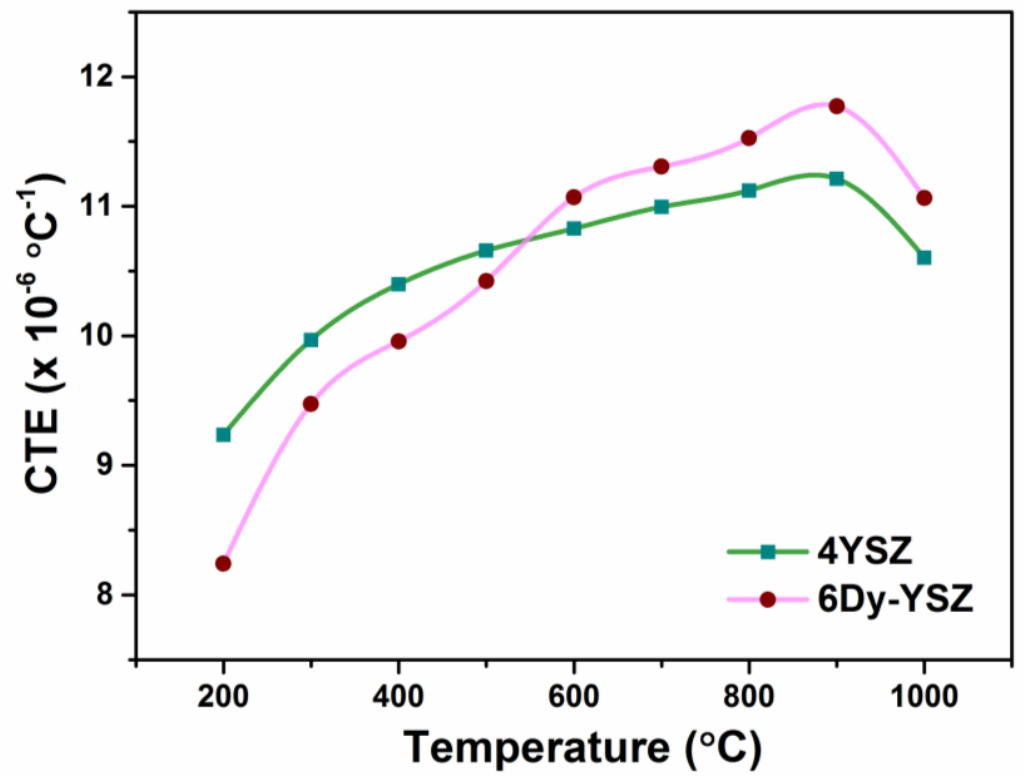

Figure 9. Comparison of the coefficient of thermal expansion between 4YSZ and $\mathrm{Dy}_{0.06} \mathrm{Y}_{0.072} \mathrm{Zr}_{0.868} \mathrm{O}_{1.934}$ 


\subsection{Thermochemical Compatibility}

Thermochemical compatibility with $\mathrm{Al}_{2} \mathrm{O}_{3}$ at high temperature is studied via a sol-gel route. The XRD patterns of powder mixtures before and after the calcination are depicted in Figure 10, suggesting that the thermochemical compatibility with $\mathrm{Al}_{2} \mathrm{O}_{3}$ can be maintained at temperatures up to $1500^{\circ} \mathrm{C}$. No diffraction peaks from the reaction products have been identified. This citric acid based sol-gel method can achieve a more homogeneous mixture of $\mathrm{Al}_{2} \mathrm{O}_{3}$ and multi-component doped $\mathrm{ZrO}_{2}$ powders, hence providing a much severer condition to assess the compatibility as compared with a solid-state reaction method.

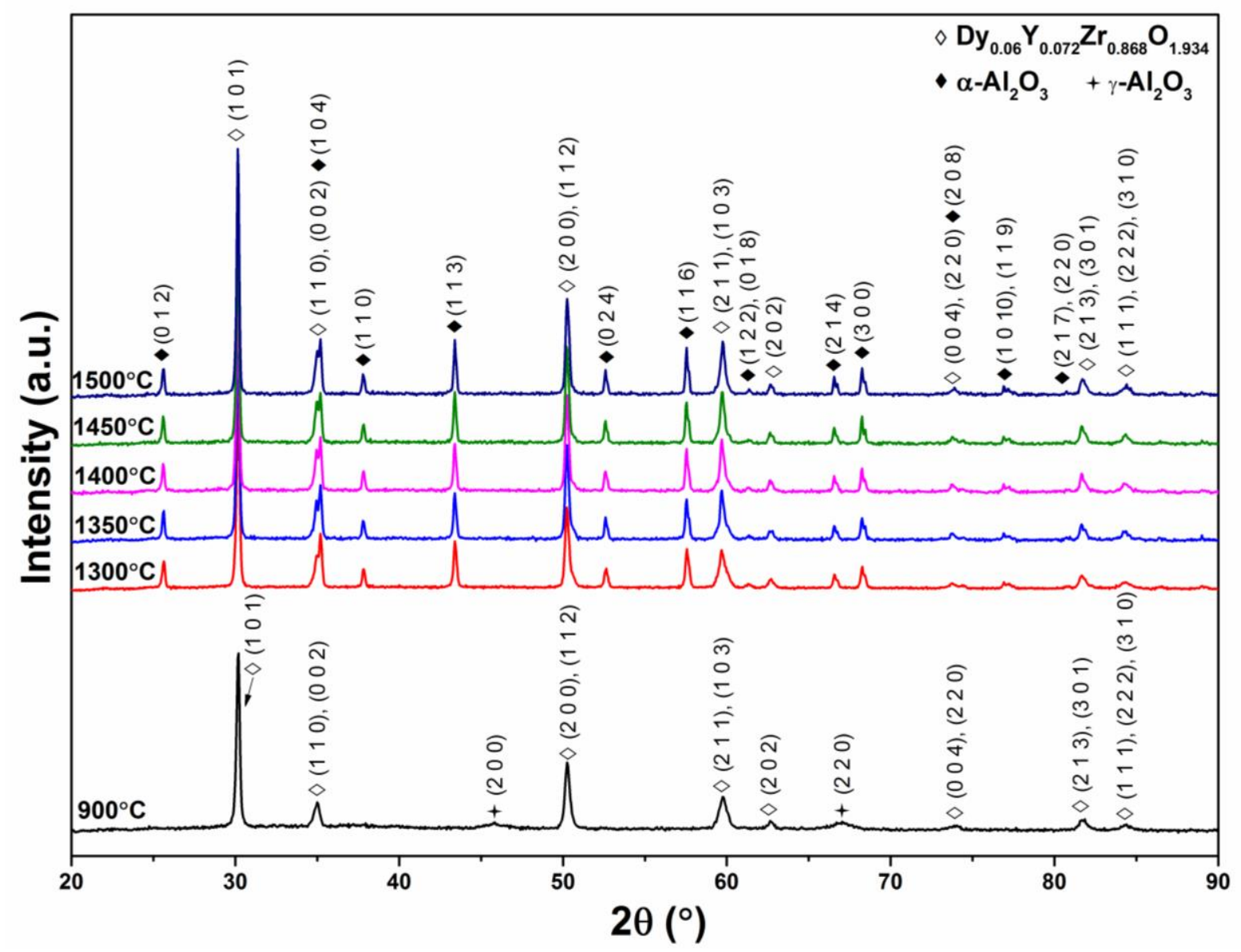

Figure 10. XRD patterns of the powder mixture via high-temperature calcination of Dy $0.06 \mathrm{Y}_{0.072} \mathrm{Zr}_{0.868} \mathrm{O}_{1.934}$ and $\mathrm{Al}_{2} \mathrm{O}_{3}$

\section{Conclusions}

In summary, tetragonal $\mathrm{Dy}_{0.06} \mathrm{Y}_{0.072} \mathrm{Zr}_{0.868} \mathrm{O}_{1.934}$ has been synthesized via a $\mathrm{Zr}(\mathrm{OPr})_{4}$ based sol-gel method. The addition of a small amount of $\mathrm{Dy}^{3+}$ can maintain the tetragonal structure. For $\mathrm{Dy}_{0.06} \mathrm{Y}_{0.072} \mathrm{Zr}_{0.868} \mathrm{O}_{1.934}$, the thermal conductivity is lower than that of $4 \mathrm{YSZ}$ and the coefficient of thermal expansion can be increased compared with that of 4YSZ. The trend of 
the calculated thermal conductivity via MD simulation corresponds well with the measured value. The thermochemical compatibility with $\mathrm{Al}_{2} \mathrm{O}_{3}$ can be maintained up to $1500^{\circ} \mathrm{C}$. The tetragonal $\mathrm{Dy}_{0.06} \mathrm{Y}_{0.072} \mathrm{Zr}_{0.868} \mathrm{O}_{1.934}$ can be considered as promising materials used in ultra-high temperature applications such as thermal barrier materials in gas turbines to improve the operation temperature and to reduce emissions.

\section{Acknowledgements}

The research facilities and funding provided by the UCL Institute for Materials Discovery are gratefully acknowledged. We are also grateful for access to the University of Nottingham's High Performance Computing Facility. We would also like to thank Dr R. S. Perry at UCL for helping with performing the neutron diffraction measurement and for the useful technical discussion.

\section{References}

[1] N.P. Padture, M. Gell, E.H. Jordan. Thermal barrier coatings for gas-turbine engine applications, Science 296 (2002) 280-284.

[2] J.A. Kilner. Ionic conductors: feel the strain, Nature Materials 7 (2008) 838-839.

[3] H. Jin, M. Breedon, Y. Tanaka, N. Miura. Fe-based solid reference electrode utilized in YSZ-based oxygen sensor, ECS Electrochemistry Letters 2 (2013) B1-B3.

[4] A.J. Steckl, J.M. Zavada. Photonic applications of rare-earth-doped materials, MRS Bulletin 24 (1999) 16-20.

[5] J.R. Nicholls, R.G. Wellman, R. Steenbarkker, J. Feist. Self diagnostic, EB-PVD thermal barrier coatings, Advances in Science and Technology 72 (2010) 65-74.

[6] I.G. Wright, T.B. Gibbons. Recent developments in gas turbine materials and technology and their implications for syngas firing, TMS06: Symposium on Materials in Clean Power Systems 32 (2007) 3610-3621.

[7] H. Zhao, C.G. Levi, H.N.G. Wadley. Molten silicate interactions with thermal barrier coatings, Surface \& Coatings Technology 251 (2014) 74-86.

[8] X. Cao, R. Vassen, D. Stoever. Ceramic materials for thermal barrier coatings, Journal of the European Ceramic Society 24 (2004) 1-10.

[9] X. Cao, R. Vassen, W. Fischer, F. Tietz, W. Jungen, D. Stöver. Lanthanum-cerium oxide as a thermal-barrier-coating material for high-temperature applications, Advanced Materials 15 (2003) 1438-1442.

[10] H. Lu, C.-A. Wang, C. Zhang. Influence of $\mathrm{Ln}^{3+}$ and $\mathrm{B}^{3+}$ ions so-substitution on thermophysical properties of $\mathrm{LnMB}_{11} \mathrm{O}_{19}$-type magnetoplumbite $\mathrm{LaMgAl}_{11} \mathrm{O}_{19}$ for advanced thermal barrier coatings, Journal of the American Ceramic Society 96 (2013) 1063-1066.

[11] J. Wu, X. Wei, N.P. Padture, P.G. Klemens, M. Gell, E. García, P. Miranzo, M.I. Osendi. Low-thermal-conductivity rare-earth zirconates for potential thermal-barriercoating applications, Journal of the American Ceramic Society 85 (2004) 3031-3035. 
[12] N.P. Bansal, D. Zhu. Effects of doping on thermal conductivity of pyrochlore oxides for advanced themral barrier coatings, Materials Science and Engineering A 459 (2007) 192-195.

[13] X. Ren, C. Wan, M. Zhao, J. Yang, W. Pan. Mechanical and thermal properties of finegrained quasi-eutectoid $\left(\mathrm{La}_{1-\mathrm{x}} \mathrm{Yb}_{\mathrm{x}}\right)_{2} \mathrm{Zr}_{2} \mathrm{O}_{7}$ ceramics, Journal of the European Ceramic Society 35 (2015) 3145-3154.

[14] R.M. Leckie, S. Krämer, M. Rühle, C.G. Levi. Thermochemical compatibility between alumina and $\mathrm{ZrO}_{2}-\mathrm{GdO}_{3 / 2}$ thermal barrier coatings, Acta Materialia 53 (2005) 32813292.

[15] R. Darolia. Thermal barrier coatings technology: critical review, progress update, remaining challenges and prospects, International Materials Reviews 58 (2013) 315-348.

[16] C. Mercer, J.R. Williams, D.R. Clarke, A.G. Evans. On a ferroelastic mechanism governing the toughness of metastable tetragonal-prime $\left(\mathrm{t}^{\prime}\right)$ yttria-stabilized zirconia, Proceedings of the Royal Society A 463 (2007) 1393-1408.

[17] R.H.J. Hannink, P.M. Kelly, B.C. Muddle. Transformation toughening in zirconiacontaining ceramics, Journal of the American Ceramic Society 83 (2000) 461-487.

[18] J.R. Brandon, R. Taylor. Phase stability of zirconia-based thermal barrier coatings Part 1. zirconia-yttria alloys, Surface and Coatings Technology 46 (1991) 75-90.

[19] C. Viazzi, J.-P. Bonino, F. Ansart, A. Barnabé. Structural study of metastable tetragonal YSZ powders produced via a sol-gel route, Journal of Alloys and Compounds 452 (2008) 377-383.

[20] L. Lelait, S. Alpérine. TEM investigations of high toughness non-equilibrium phases in the $\mathrm{ZrO}_{2}-\mathrm{Y}_{2} \mathrm{O}_{3}$ system, Scripta Metallurgica et Materialia 25 (1991) 1815-1820.

[21] M.R. Loghman-Estarki, M. Hajizadeh-Oghaz, H. Edris, R.S. Razavi. Comparative studies on synthesis of nanocrystalline $\mathrm{Sc}_{2} \mathrm{O}_{3}-\mathrm{Y}_{2} \mathrm{O}_{3}$ doped zirconia (SYDZ) and YSZ solid solution via modified and classic Pechini method, CrystEngComm 15 (2013) 5898-5909.

[22] P.K. Schelling, S.R. Phillpot, P. Keblinski. Comparison of atomic-level simulation methods for computing thermal conductivity, Physical Review B 65 (2001) 1-6.

[23] J. Shiomi. Nonequilibrium molecular dynamics methods for lattice heat conduction calculations, Annual Review of Heat Transfer 17 (2014) 177-203.

[24] P.K. Schelling, S.R. Phillpot, R.W. Grimes. Optimum pyrochlore compositions for low thermal conductivity, Philosophical Magazine Letters 84 (2004) 127-137.

[25] S. Patrick K. Thermal conductivity of A-site doped pyrochlore oxides studied by molecular-dynamics simulation, Computational Materials Science 48 (2010) 336-342.

[26] A.R. West. Basic solid state chemistry, John Wiley \& Sons Ltd., 1999.

[27] P. Canton, G. Fagherazzi, R. Frattini, P. Riello. Stabilization of cubic Na-modified $\mathrm{ZrO}_{2}$ : a neutron diffraction study, Journal of Applied Crystallography 32 (1999) 475-480.

[28] J. Fenech, M. Dalbin, A. Barnabe, J.P. Bonino, F. Ansart. Sol-gel processing and characterization of (RE-Y)-zirconia powders for thermal barrier coatings, Powder Technology 208 (2011) 480-487.

[29] ISIS. Wish instrument. 2015.

[30] K.W. Schlichting, N.P. Padture, P.G. Klemens. Thermal conductivity of dense and porous yttria-stabilized zirconia, Journal of Materials Science 36 (2001) 3003-3010.

[31] P.K. Schelling, S.R. Phillpot. Mechanism of thermal transport in zirconia and yttriastabilized zirconia by molecular dynamics simulation, Journal of the American Ceramic Society 84 (2001) 2997-3007.

[32] P.K. Schelling, S.R. Phillpot, D. Wolf. Mechanism of the cubic-to-tetragonal phase transition in zirconia and yttria-stabilized zirconia by molecular-dynamics simulation, Journal of the American Ceramic Society 84 (2001) 1609-1619. 
[33] D. Wolf, P. Keblinski, S.R. Phillpot, J. Eggebrecht. Exact method for the simulation of Coulombic systems by spherically truncated, pairwise $\mathrm{r}^{-1}$ summation, The Journal of Chemical Physics 110 (1999) 8254-8282.

[34] C.J. Fennell, J.D. Gezelter. Is the Ewald summation still necessary? Pairwise alternatives to the accepted standard for long-range electrostatics, The Journal of Chemical Physics 124 (2006) 1-12.

[35] C.R. Stanek, L. Minervini, R.W. Grimes. Nonstoichiometry in $\mathrm{A}_{2} \mathrm{~B}_{2} \mathrm{O}_{7}$ pyrochlores, Journal of the American Ceramic Society 85 (2002) 2792-2798.

[36] P. Jund, R. Jullien. Molecular-dynamics calculation of the thermal conductivity of vitreous silica, Physical Review B 59 (1999) 13707-13711.

[37] G.J. Mcinityre. Neutron scattering's influence on crystallography, Neutron News 25 (2014) 19-22.

[38] L. Qu, K.-L. Choy. Thermophysical and thermochemical properties of new thermal barrier materials based on $\mathrm{Dy}_{2} \mathrm{O}_{3}-\mathrm{Y}_{2} \mathrm{O}_{3}$ co-doped zirconia, Ceramics International 40 (2014) 11593-11599.

[39] S. Heiroth, R. Frison, J.L.M. Rupp, T. Lippert, E.J. Barthazy Meier, E. Müller Gubler, M. Döbeli, K. Conder, A. Wokaun, L.J. Gauckler. Crystallization and grain growth characteristics of yttria-stabilized zirconia thin films grown by pulsed laser deposition, Solid State Ionics 191 (2011) 12-23.

[40] Y. Wang, F. Yang, P. Xiao. Role and determining factor of substitutional defects on thermal conductivity: a study of $\mathrm{La}_{2}\left(\mathrm{Zr}_{1-\mathrm{x}} \mathrm{B}_{\mathrm{x}}\right)_{2} \mathrm{O}_{7}(\mathrm{~B}=\mathrm{Hf}, \mathrm{Ce}, 0 \leqslant \mathrm{x} \leqslant 0.5)$ pyrochlore solid solutions, Acta Materialia 68 (2014) 106-115.

[41] D. Mikulić, B. Milovanović. TCi system for non-destructive determination the thermal properties of materials. 10th European Conference on Non-Destructive Testing. Moscow, Russia, 2010. p.1-10.

[42] D.R. Clarke. Materials selection guidelines for low thermal conductivity thermal barrier coatings, Surface and Coatings Technology 163-164 (2003) 67-74.

[43] A.M. Limarga, S. Shian, R.M. Leckie, C.G. Levi, D.R. Clarke. Thermal conductivity of single- and multi-phase composition in the $\mathrm{ZrO}_{2}-\mathrm{Y}_{2} \mathrm{O}_{3}-\mathrm{Ta}_{2} \mathrm{O}_{5}$ system, Journal of the European Ceramic Society 34 (2014) 3085-3094.

[44] H. Hayashi, T. Saitou, N. Maruyama, H. Inaba, K. Kawamura, M. Mori. Thermal expansion coefficient of yttria stabilized zirconia for various yttria contents, Solid State Ionics 17 (2005) 613-619.

[45] C.L. Wan, W. Pan, Q. Xu, Y.X. Qin, J.D. Wang, Z.X. Qu, M.H. Fang. Effect of point defects on the thermal transport properties of $\left(\operatorname{La}_{\mathrm{x}} \mathrm{Gd}_{1-\mathrm{x}}\right)_{2} \mathrm{Zr}_{2} \mathrm{O}_{7}$ : experiment and theoretical model, Physical Review B 74 (2006) 1-9.

[46] M. Zhao, X. Ren, W. Pan. Effect of lattice distortion and disordering on the mechanical properties of titania-doped yttria-stabilized zirconia, Journal of the American Ceramic Society 97 (2014) 1566-1571.

[47] X. Wang, H. Xiang, X. Sun, J. Liu, F. Hou, Y. Zhou. Mechanical properties and damage tolerance of bulk $\mathrm{Yb}_{3} \mathrm{Al}_{5} \mathrm{O}_{12}$ ceramic, Journal of Materials Science \& Technology 31 (2015) 369-374.

[48] E. Kisi, Y. Ma. Debye temperature, anharmonic thermal motion and oxygen nonstoichiometry in yttria stabilized cubic zirconia, Journal of Physics: Condensed Matter 10 (1998) 3823-3832.

[49] F. Yang, X. Zhao, P. Xiao. The effects of temperature and composition on the thermal conductivities of $\left[\left(\mathrm{ZrO}_{2}\right)_{1-\mathrm{x}}\left(\mathrm{CeO}_{2}\right)_{\mathrm{x}}\right]_{0.92}\left(\mathrm{Y}_{2} \mathrm{O}_{3}\right)_{0.08}(0 \leqslant \mathrm{x} \leqslant 1)$ solid solutions, Acta Materialia 60 (2012) 914-922. 
[50] S.R. Choi, D. Zhu, R.A. Miller. Effect of sintering on mechanical and physical properties of plasma-sprayed thermal barrier coatings, Journal of the American Ceramic Society 88 (2004) 2859-2867.

[51] X. Xia, R. Oldman, R. Catlow. Computational modeling study of bulk and surface of yttria-stabilized cubic zirconia, Chemistry of Materials 21 (2009) 3576-3585.

[52] D.M. Zhu, Y.L. Chen, R.A. Miller. Defect clustering and nano-phase structure characterization of multi-component rare earth oxide doped zirconia-yttria thermal barrier coatings. in: Kriven WM, Lin HT, (Eds.). 27th International Cocoa Beach Conference on Advanced Ceramics and Composites: A, vol. 24. Amer Ceramic Soc, Westerville, 2003. pp. 525-534.

[53] A. Rauf, Q. Yu, L. Jin, C. Zhou. Microstructure and thermal properties of nanostructured lanthana-doped yttria-stabilized zirconia thermal barrier coatings by air plasma spraying, Scripta Materialia 66 (2012) 109-112.

[54] K. Scheerschmidt. Empirical molecular dynamics: possibilities, requirements, and limitations. in: Drabold DA, Estreicher SK, (Eds.). Theory of Defects in Semiconductors. 2007. pp. 213-244.

[55] D.R. Lide, W.M. Haynes. CRC handbook of chemistry and physics: a ready-reference book of chemical and physical data, CRC Press, Taylor and Francis Group, 2009.

[56] Z. Qu, C. Wan, W. Pan. Thermal expansion and defect chemistry of MgO-doped $\mathrm{Sm}_{2} \mathrm{Zr}_{2} \mathrm{O}_{7}$, Chemistry of Materials 19 (2007) 4913-4918. 